\title{
Progressive Motor Cortex Functional Reorganization Following 6-Hydroxydopamine Lesioning in Rats
}

\author{
Riccardo Viaro, ${ }^{1,2,3}$ Michele Morari, ${ }^{1,2}$ and Gianfranco Franchi ${ }^{3}$ \\ ${ }^{1}$ Department of Experimental and Clinical Medicine, Section of Pharmacology, ${ }^{2}$ Center for Neuroscience and National Institute for Neuroscience, and \\ ${ }^{3}$ Department of Biological Sciences and Advanced Therapies, Section of Human Physiology, University of Ferrara, 44100 Ferrara, Italy
}

\begin{abstract}
Many studies have attempted to correlate changes of motor cortex activity with progression of Parkinson's disease, although results have been controversial. In the present study we used intracortical microstimulation (ICMS) combined with behavioral testing in 6-hydroxydopamine hemilesioned rats to evaluate the impact of dopamine depletion on movement representations in primary motor cortex (M1) and motor behavior. ICMS allows for motor-effective stimulation of corticofugal neurons in motor areas so as to obtain topographic movements representations based on movement type, area size, and threshold currents. Rats received unilateral 6-hydroxydopamine in the nigrostriatal bundle, causing motor impairment. Changes in M1 were time dependent and bilateral, although stronger in the lesioned than the intact hemisphere. Representation size and threshold current were maximally impaired at $15 \mathrm{~d}$, although inhibition was still detectable at 60-120 d after lesion. Proximal forelimb movements emerged at the expense of the distal ones. Movement lateralization was lost mainly at $30 \mathrm{~d}$ after lesion. Systemic L-3,4-dihydroxyphenylalanine partially attenuated motor impairment and cortical changes, particularly in the caudal forelimb area, and completely rescued distal forelimb movements. Local application of the $\mathrm{GABA}_{\mathrm{A}}$ antagonist bicuculline partially restored cortical changes, particularly in the rostral forelimb area. The local anesthetic lidocaine injected into the $\mathrm{M} 1$ of the intact hemisphere restored movement lateralization in the lesioned hemisphere. This study provides evidence for motor cortex remodeling after unilateral dopamine denervation, suggesting that cortical changes were associated with dopamine denervation, pathogenic intracortical GABA inhibition, and altered interhemispheric activity.
\end{abstract}

\section{Introduction}

Parkinson's disease (PD) is a complex and progressive neurological disorder characterized by motor and nonmotor symptoms (Galvan and Wichmann, 2008). Motor symptoms such as akinesia/bradykinesia, rigidity, and tremor at rest are essentially caused by the degeneration of dopamine (DA) neurons located in substantia nigra compacta followed by deafferentation of striatum and other projection areas. Several studies have attempted to investigate the relationship between motor cortex activity and PD progression, although results have been controversial. Cortical activity has been found to be reduced (Escola et al., 2002, 2003; Buhmann et al., 2003; Lefaucheur, 2005; Parr-Brownlie and Hyland, 2005; Brown et al., 2009), increased (Sabatini et al., 2000; Pelled et al., 2002; Seiss and Praamstra, 2004, Lefaucheur, 2005), or unchanged (Dick et al., 1984; Metz et al., 2004) in parkinsonian animals as well as PD patients. This variability can be attributed to experimental reasons (i.e., methods, time, and region of interest). Indeed, analysis performed in PD patients at different stages of progression indicated a dynamic reorganization of cor-

Received Oct. 14, 2010; revised Feb. 1, 2011; accepted Feb. 3, 2011.

This work was supported by a local grant from the University of Ferrara to $G$. Franchi and by a grant from the Italian Ministry of the University to M. Morari [Fondo Investimenti Ricerca Base (FIRB) Internazionalizzazione No. RBIN047W33].

Correspondence should be addressed to Dr. Riccardo Viaro, Department of Biomedical Sciences and Advanced Therapies, Section of Human Physiology, University of Ferrara, Via Fossato di Mortara 17-19, 44100 Ferrara, Italy. E-mail: riccardo.viaro@unife.it.

DOI:10.1523/JNEUROSCI.5394-10.2011

Copyright $\odot 2011$ the authors $\quad 0270-6474 / 11 / 314544-11 \$ 15.00 / 0$ tical functions, in particular a displacement of the corticomotor representation of the hand (Thickbroom et al., 2006) as well as changes of glucose metabolism in primary motor (M1) and prefrontal cortex (Huang et al., 2007). Intracortical microstimulation (ICMS) has proved a reliable technique for detecting functional changes in M1 representations following brain lesions, revealing that M1 undergoes a process of multistage reorganization beginning minutes and ending weeks after lesion (Sanes et al., 1990; Toldi et al., 1996; Huntley, 1997; Franchi, 2000, 2002; Sanes and Donoghue, 2000; Maggiolini et al., 2007, 2008). Nonetheless, a previous ICMS study in a neurodegeneration model of parkinsonism showed no change in M1 map between 27 and $58 \mathrm{~d}$ after unilateral 6-hydroxydopamine (6-OHDA) lesion (Metz et al., 2004). However, to prove the role of endogenous DA, bilateral intrastriatal 6-OHDA or systemic haloperidol injections reduced the size of motor representations at $15 \mathrm{~d}$ or $15 \mathrm{~min}$ after administration, respectively (Brown et al., 2009). Therefore, the time of mapping may be crucial to follow M1 reorganization after manipulation of DA transmission. Here we used ICMS in rats under light anesthesia, which allows us to evoke a pattern of movements comparable to those reported in previous ICMS studies (stages III-1 and III-2) (Friedberg et al., 1999). ICMS allowed exploration of the adaptive changes in M1 output, defined as a combination of threshold current required to evoke movements, size of movement representations, and type of evoked movement. ICMS was performed at 3, 15, 30, 60, and $120 \mathrm{~d}$ after unilateral 6-OHDA lesion in parallel with behavioral testing under awake conditions. Since significant cortical changes were observed following 
6-OHDA, we investigated the DA dependence of M1 dysregulation by measuring motor and electrophysiological responses to the DA precursor L-3,4-dihydroxyphenylalanine (L-dopa). Because L-dopa only partially restored the cortical output, we explored the role of intracortical GABA inhibition as well as the contribution of interhemispheric connections (Schneider et al., 2002; Li et al., 2007) with local treatments using the $\mathrm{GABA}_{\mathrm{A}}$ receptor antagonist bicuculline and the voltage-dependent $\mathrm{Na}^{+}$ channel blocker lidocaine, respectively.

\section{Materials and Methods}

\section{Animals}

Adult male Wistar rats (300-350 g at the time of experiment; Harlan) were kept under regular lighting conditions ( $12 \mathrm{~h}$ light/dark cycle) and given food and water ad libitum. This study was compliant with the European Council Directive of 24 November, 1986 (86/609/EEC), and approved by the Ethical Committee of the University of Ferrara and the Italian Ministry of Health. Adequate measures were taken to minimize animal pain as well as the number of animals used.

\section{Experimental design}

The first set of experiments (experiment 1) was aimed at the analysis of motor phenotype and M1 output in hemiparkinsonian rats. Animals were made hemiparkinsonian by unilateral 6-OHDA injection in the medial forebrain bundle (MFB). Motor activity was evaluated in awake rats by a battery of behavioral tests, namely the bar, drag, and elevated body swing tests. These tests were performed at different time points (i.e., $3,15,30,60$, and $120 \mathrm{~d}$ after 6 -OHDA injection; 5 rats each time point). Just after completion of motor testing, animals were anesthetized and M1 mapping was performed by ICMS. The second set of experiments (experiment 2) was aimed at the study of the mechanisms underlying M1 changes. To prove the role of endogenous DA, the ability of systemic L-dopa to rescue motor activity and cortical output was assessed in two groups of rats ( $n=5$ each) at 15 and $60 \mathrm{~d}$ after 6-OHDA injection. To investigate whether these functional changes were due to an increased intracortical GABA inhibition, the effect of local application of the $\mathrm{GABA}_{\mathrm{A}}$ receptor antagonist bicuculline in the lesioned hemisphere was studied at 15 and $60 \mathrm{~d}$ ( $n=5$ each). Finally, to investigate whether the unlesioned hemisphere affected cortical output at the lesioned one, the voltage-dependent $\mathrm{Na}^{+}$-channel blocker lidocaine was applied in the unlesioned hemisphere (at $30 \mathrm{~d}$ ) in an additional group of 5 rats.

\section{6-OHDA lesion}

Unilateral lesion of DA neurons was induced in ketamine-anesthetized rats as described previously (Marti et al., 2007). Eight micrograms of 6-OHDA (in $4 \mu \mathrm{l}$ of saline containing $0.02 \%$ ascorbic acid) were stereotaxically injected in MFB according to the following coordinates from bregma: anteroposterior (AP), $-4.4 \mathrm{~mm}$; mediolateral (ML), $-1.2 \mathrm{~mm}$; ventrodorsal (VD), $-7.8 \mathrm{~mm}$ below dura (Paxinos and Watson, 1982). We chose not to protect noradrenergic fibers with desmethylimipramine to more closely model the clinical condition, since noradrenergic damage plays a significant role during the progress of the illness (Zarow et al., 2003).

\section{Pharmacological treatments}

L-Dopa and bicuculline were administered at 15 and $60 \mathrm{~d}$ after 6-OHDA lesioning, whereas lidocaine was administered after $30 \mathrm{~d}$. ICMS started 10 min after pharmacological treatments.

L-Dopa. L-Dopa ( $6 \mathrm{mg} / \mathrm{kg}$ in combination with benserazide $15 \mathrm{mg} / \mathrm{kg}$ ) (Marti et al., 2007) was administered systemically (i.p.) in a volume of 10 $\mu \mathrm{l} / \mathrm{g}$ body weight.

Bicuculline. Under surgical stereomicroscopy, the dura at the M1 ipsilateral to the 6-OHDA injection side was removed, and a $30 \mu$ solution of $50 \mu \mathrm{M}$ bicuculline was applied to the cortical surface (Stojic et al., 2000) using a Gilson micropipette. This protocol of bicuculline application has been reported to provide effective $\mathrm{GABA}_{\mathrm{A}}$ receptor blockade in all cortical layers (Stojic et al., 2000). The temperature of the solution was kept at $36-38^{\circ} \mathrm{C}$, and one to two supplementary applications were performed to maintain the cortex moist. M1 was mapped before and after drug treatment in each animal to limit interindividual variability.

Lidocaine. Since lidocaine was effective up to $1 \mathrm{~mm}$ away from the injection site (Maggiolini et al., 2008), three lidocaine injections ( $12 \mu \mathrm{l}$ of a $3 \%$ solution) were stereotaxically performed within the forelimb area at three different sites along the $\mathrm{AP}$ axis $(\mathrm{AP}+1, \mathrm{AP}+2, \mathrm{AP}+3), \mathrm{ML}+3$, and VD $1 \mathrm{~mm}$ below the cortical surface. Lidocaine was slowly injected at $4 \mu \mathrm{l} / \mathrm{min}$, and the needle was left in place for an additional $2 \mathrm{~min}$ to prevent the substance from refluxing. Cortical inactivation was maintained by one to two supplementary injections of lidocaine and confirmed by remapping the injected sites every 30 min (Maggiolini et al., 2008).

\section{Behavioral studies}

Motor activity (akinesia, bradykinesia, rigidity, and asymmetry) was evaluated immediately before ICMS by three behavioral tests providing complementary information on different motor parameters: (1) the "bar test" (Sanberg et al., 1988), which measures the ability of the rat to respond to an externally imposed static posture; (2) the "drag test" (Marti et al., 2005), a modification of the "wheelbarrow test" (Schallert et al., 1979), which measures the ability of the rat to balance its body posture using forelimbs in response to an externally imposed dynamic stimulus (backward dragging); and (3) the "elevated body swing test" (Borlongan and Sanberg, 1995), which measures the ability of the rat to control its body position in empty space by recruiting several muscle sections (paws, trunk, neck, etc.).

Bar test. Each rat was placed gently on a table and the contralateral and ipsilateral forepaws were placed alternatively on blocks of increasing heights $(3,6$, and $9 \mathrm{~cm})$. Total time (in seconds) spent by each paw on the blocks (defining akinesia) was recorded (cutoff time of $20 \mathrm{~s}$ ).

Drag test. Each rat was gently lifted from the tail (allowing forepaws on the table) and dragged backwards at a constant speed $(\sim 20 \mathrm{~cm} / \mathrm{s})$ for a fixed distance $(100 \mathrm{~cm})$. The number of steps made by each paw was counted by two separate observers.

Elevated body swing test. The test was conducted in a dark plastic box $(40 \times 40 \times 50 \mathrm{~cm})$. Initially, each rat was allowed to habituate in the box for $5 \mathrm{~min}$ and then it was elevated $3 \mathrm{~cm}$ above the ground by holding its tail. When the animal turned with its body (i.e., head and trunk) $>30^{\circ}$ to either side of the vertical axis, a swing was counted. The direction and the number of swings carried out in $60 \mathrm{~s}$ were recorded.

Previous studies have shown that unilateral 6-OHDA injections were associated with motor asymmetry and overall motor impairment, resulting in an increased immobility time and reduced stepping activity (Marti et al., 2005, 2007). Moreover, a decrease in the number of swings made toward the contralateral body side has been found (our unpublished data) (Borlongan and Sanberg, 1995).

\section{ICMS}

Anesthesia was induced by ketamine hydrochloride ( $80 \mathrm{mg} / \mathrm{kg}$, i.p. $)$ and maintained throughout the experiment by supplementary ketamine injections $(25 \mathrm{mg} / \mathrm{kg}$, i.m.) so that long-latency, sluggish hindlimb withdrawal was achieved by pinching of the hind foot. This level of anesthesia was light (stages III-1 and III-2) (Friedberg et al., 1999) and allowed us to evoke a pattern of movements comparable among animals, likely without affecting the ICMS results. Body temperature was maintained at $36-38^{\circ} \mathrm{C}$ with a heat lamp. The animal was placed in a Kopf stereotaxic apparatus, and a large craniotomy was performed over the frontal cortex. The dura remained intact (or removed under surgical stereomicroscopy in bicuculline experiments) and kept moist with saline solution. ICMS began immediately after behavioral testing in experiment 1 and $10 \mathrm{~min}$ after pharmacological treatments in experiment 2 .

Mapping procedure. Cortical mapping was aimed at defining the extent of movement representations and the current threshold required to elicit movements. The mapping procedure (Franchi, 2000) was similar to that described by Donoghue and Wise (1982), and Sanes et al. (1990). Briefly, the electrode penetrations were regularly spaced out over a $500 \mu \mathrm{m}$ grid. Adjustments in the coordinate grid were sometimes necessary to keep the electrode from penetrating a blood vessel. These adjustments were not reported in the reconstructed maps. When the adjustment exceeded 50 


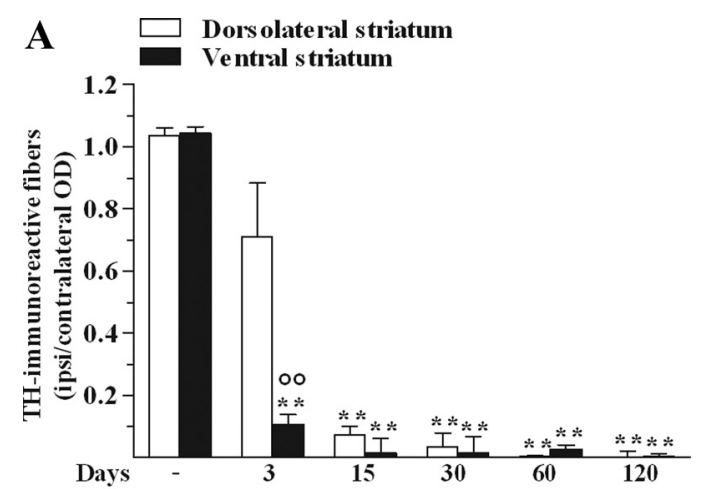

B
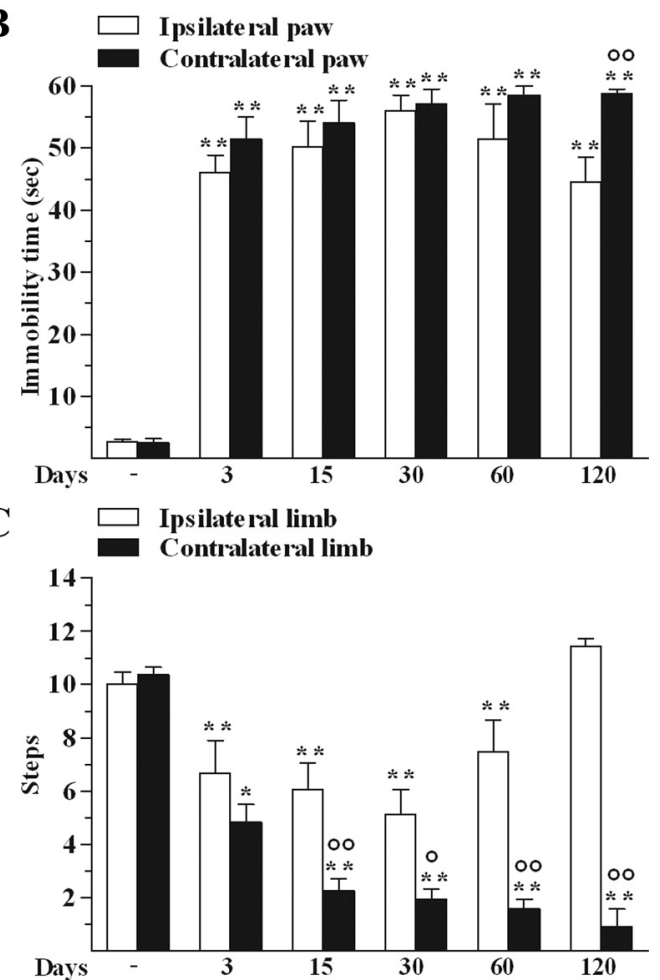

D

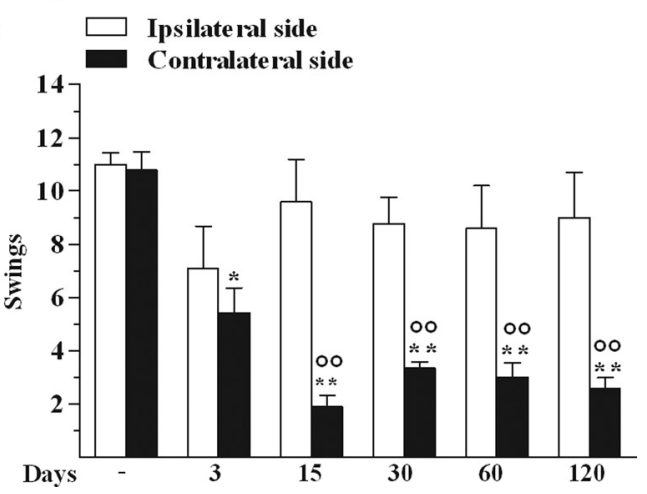

Figure 1. Unilateral 6-OHDA injection in rats destroyed DA terminals in the ipsilateral striatum and reduced motor activity. $0 \mathrm{D}$ of TH-immunoreactive fibers in the dorsolateral and ventral striatum $(\boldsymbol{A})$ and motor activity in the bar $(\boldsymbol{B}), \operatorname{drag}(\boldsymbol{C})$, and elevated body swing $(\boldsymbol{D})$ test were performed in control and 6-0HDA rats at 3, 15, 30,60, and $120 \mathrm{~d}$ after lesion. No effect was observed after vehicle injection. Data are means \pm SEM of five determinations per group and are expressed as the ratio between $\mathrm{OD}$ in the lesioned (ipsilateral) and unlesioned (contralateral) side $(\boldsymbol{A})$, and as absolute values ( $\boldsymbol{B}-\boldsymbol{D}$; seconds (sec), steps and swings, respectively). Statistical results: $\boldsymbol{A}$, Effect of treatment $\left(F_{(1,4)}=12.08, p=0.0254\right)$, time $\left(F_{(5,40)}=98.18\right.$, $p<0.0001)$ and time $\times$ treatment interaction $\left(F_{(5,40)}=7.77, p<0.0001\right)$. B, Effect of treatment $\left(F_{(1,4)}=13.13, p=0.0223\right)$ and time $\left(F_{(5,40)}=112.98, p<0.0001\right)$ but not time $\times$ treatment interaction $\left(F_{(5,40)}=1.75, p=0.15\right)$. C, Effect of treatment $\left(F_{(1,4)}=\right.$ $\mu \mathrm{m}$, the penetration at this site was not performed. Glass-insulated tungsten microelectrodes $(0.6-1 \mathrm{M} \Omega$ impedance at $1 \mathrm{kHz})$ mounted on electrical microadvancer (Burleigh Inchworm System) were used for stimulation. The electrode was lowered perpendicularly into the cortex down to $1500 \mu \mathrm{m}$ below the cortical surface (1420 $\mu \mathrm{m}$ without dura) and adjusted $\pm 200 \mu \mathrm{m}$ so as to evoke movement at the lowest threshold. This depth corresponds to layer $\mathrm{V}$ of the frontal agranular cortex (Franchi, 2000). Monophasic cathodal pulses ( $30 \mathrm{~ms}$ trains duration at $300 \mathrm{~Hz}, 200$ $\mu$ s pulse duration) at a maximum of $60 \mu \mathrm{A}$ were passed through the electrode with a minimum interval of $2.5 \mathrm{~s}$. Two separate observers were involved in the experiment: one observer, blind to the current intensity and treatment, was required to detect movements, the other to adjust current levels. Starting with a current of $60 \mu \mathrm{A}$, intensity was decreased in $5 \mu \mathrm{A}$ steps until movement was no longer evoked, and then it was increased to a level at which $\sim 50 \%$ of the stimulations elicited movement. This level defined the current threshold. If no movements or twitches were evoked at $60 \mu \mathrm{A}$, the site was considered as unexcitable. Mapping was initiated at high current because the initial polysynaptic recruitment of remote neurons optimized the detection of movements in this $500 \mu \mathrm{m}$ grid map. When movement was observed in two or more different body parts, current thresholds were determined for each component. Body parts activated by microstimulation were identified by visual inspection and/or muscle palpation. When eye movement was observed, the current threshold was determined under a surgical microscope. The areas of eye, eye-eyelid and miosis sites in each hemisphere were too small, so these sites have been collectively referred to as "eye sites."

Map construction. Representation maps at threshold current were generated from the pattern of electrode penetrations. In each hemisphere, movements were mapped to determine the extent and location of vibrissa and forelimb movement representations. Other cortical areas (e.g., those evoking eye, neck, jaw/tongue, and hindlimb movements) were too small, so these values were not considered for quantitative analysis. Each stimulated site was taken to represent a square of $0.25 \mathrm{~mm}^{2}$ of cortical surface $(0.5 \times 0.5 \mathrm{~mm})$, and a cortical area was calculated as the number of sites $\times 0.25 \mathrm{~mm}^{2}$. Map borders were defined as the midpoint between sites with different movement thresholds. If a site eliciting movement was flanked by a site that showed no movement upon stimulation of up to $60 \mu \mathrm{A}$, the borderline for the represented movement was set at $250 \mu \mathrm{m}$ from the movement site. In our analysis, an unexcitable area was calculated from the number of unexcitable sites in the region between 0.75 and $4.25 \mathrm{~mm}$ (AP) and 1.25 and $4.25 \mathrm{~mm}$ (ML) from bregma. This part of the frontal cortex corresponded to the vibrissa and forelimb site distribution. Hindlimb representation delimited the posterior boundary of the vibrissa and forelimb representation, and ineffective sites formed the basis for delineating the rostral M1 border. Based on physiological and anatomical evidence (Neafsey and Sievert, 1982; Neafsey et al., 1986; Rouiller et al., 1993), we distinguished two subregions within the forelimb area, namely the caudal and rostral areas (posterior and anterior to AP, $3.25 \mathrm{~mm}$, respectively). Forelimb movements were classified as either distal (wrist/digit) or proximal (elbow/shoulder).

\section{Histological evaluations}

At the end of the ICMS procedure, each animal was deeply anesthetized with Zoletil 100 (10 mg/kg, i.m.; Virbac Laboratories), transcardially perfused at room temperature with $20 \mathrm{~mm}$ potassium PBS (KPBS) fixed with cold $4 \%$ paraformaldehyde in KPBS at $\mathrm{pH}$ 7.4. Brains were removed, postfixed overnight, and transferred to $25 \%$ sucrose solution in KPBS for cryoprotection until they sunk. We used a freezing microtome to cut $40 \mu \mathrm{m}$ coronal sections that were collected free floating (in KPBS) for Nissl staining or tyrosine hydroxylase (TH) immunohistochemistry.

$\leftarrow$

$234.18, p=0.0001)$, time $\left(F_{(5,40)}=21.51, p<0.0001\right)$, and time $\times$ treatment interaction $\left(F_{(5,40)}=13.11, p<0.0001\right)$. D, Effect of treatment $\left(F_{(1,4)}=25.42, p=0.0073\right)$, time $\left(F_{(5,40)}=\right.$ $8.28, p<0.0001)$, and time $\times$ treatment interaction $\left(F_{(5,40)}=4.21, p<0.0036\right) .{ }^{*} p<0.05$, ${ }^{* *} p<0.01$ different from control; $p<0.05,{ }^{\circ} p<0.01$ different from dorsolateral striatum $(A)$ or ipsilateral side ( $\boldsymbol{B}-\boldsymbol{D}$; RM ANOVA followed by contrast analysis and the sequentially rejective Bonferroni's test for multiple comparisons). 

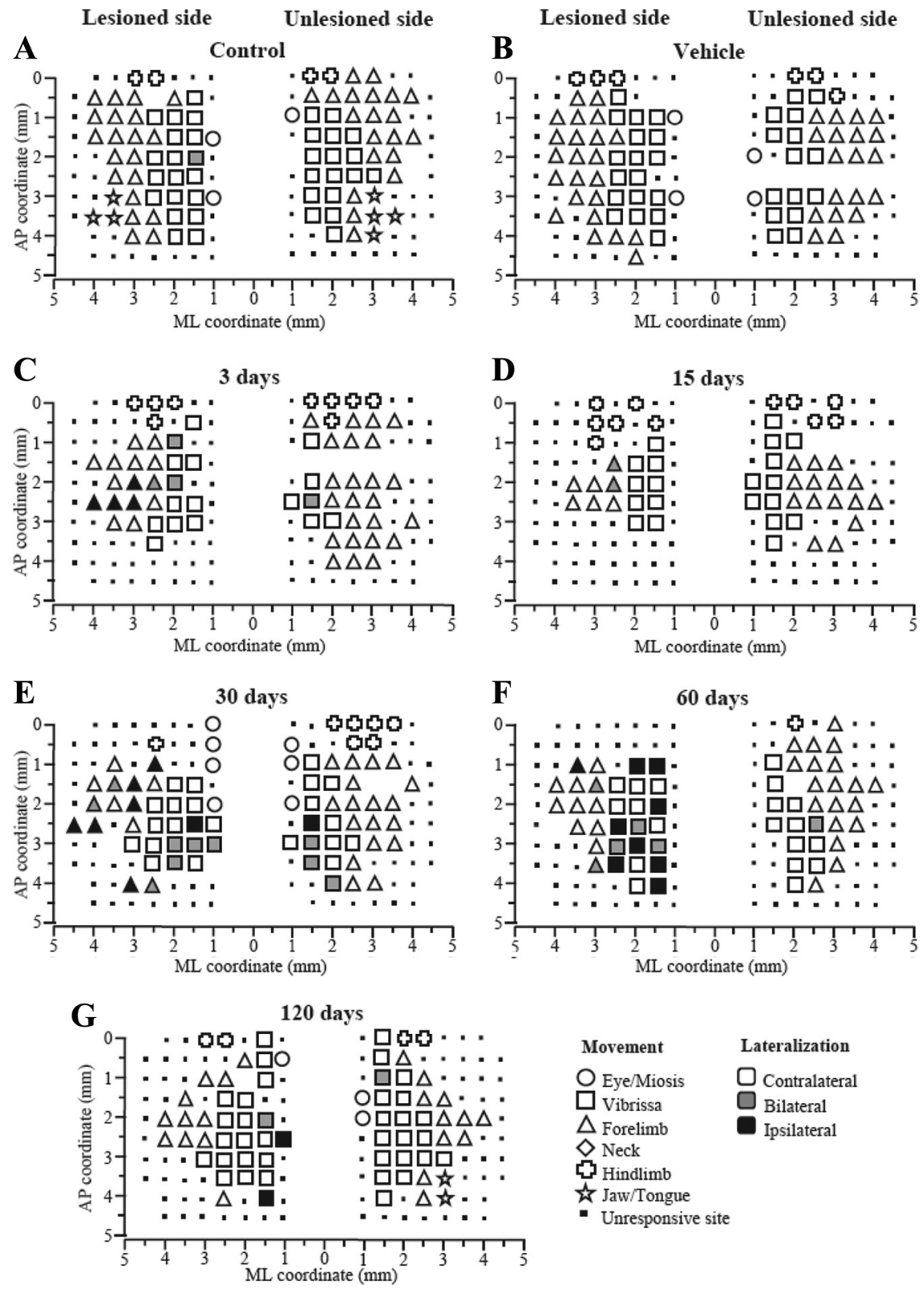

Figure 2. Unilateral 6-OHDA injection in rats affected M1 output. Representative bilateral M1 maps of movements evoked at threshold current levels in control $(\boldsymbol{A})$, sham $(\boldsymbol{B})$, and 6-0HDA rats at $3(\boldsymbol{C}), 15(\boldsymbol{D}), 30(\boldsymbol{E}), 60(\boldsymbol{F})$, and $120(\boldsymbol{G})$ days after lesion. The microelectrode was sequentially introduced to a depth of $1500 \mu \mathrm{m}$. Interpenetration distances were $500 \mu \mathrm{m}$. In these mapping schemes, frontal poles are at the bottom. Zero ( 0 ) corresponds to bregma and numbers indicate rostral distance from the bregma or lateral distance from the midline. Movement evoked at one point is indicated by symbols and movement lateralization by different gray scale. Absence of symbol (within or at the border of the maps) indicates that penetration was not performed due to the presence of a large vessel. incubation in anti-TH mouse monoclonal antibody solution (1:2000, Millipore Bioscience Research Reagents) for $16 \mathrm{~h}$ at room temperature. The sections were then rinsed in KPBS and incubated for $1 \mathrm{~h}$ in biotinylated horse anti-mouse IgG secondary antibody (1:200; Vector Laboratories). After rinsing, sections were incubated with avidin-biotin-peroxidase complex (Vector Laboratories) for $30 \mathrm{~min}$ at room temperature. After rinsing with KPBS, immunoreactivity was visualized by incubating the sections in a solution containing $0.05 \%$ 3,3-diaminobenzidine in $0.013 \% \mathrm{H}_{2} \mathrm{O}_{2}$ in $\mathrm{KPBS}$ for $\sim 1 \mathrm{~min}$. The sections were rinsed in KPBS, mounted on chrome-alum-coated slides, dried with escalating alcohol concentration, cleared in xylene and coverslipped with mounting medium. TH-immunoreactive fiber density was analyzed in two different striatal regions, namely dorsolateral and ventral striatum, using ImageJ software (Wayne Rasband, National Institutes of Health, Bethesda, MD). Optical density (OD) was corrected for nonspecific background that was measured in the corpus callosum. TH-positive fibers density was calculated as a ratio between OD in the lesioned and unlesioned sides.

Data presentation and statistical analysis Data are expressed as means \pm SEM of five determinations per group. Statistical analysis was performed by two-way repeated measures (RM) ANOVA, implemented on a spreadsheet. In the case that ANOVA yielded a significant $F$ score, post hoc analysis was performed by contrast analysis to determine differences between groups, followed by the sequentially rejective Bonferroni test to determine differences at single time point level. To analyze lidocaine effects (see Fig. 8) one-way ANOVA followed by the Newman-Keuls test was performed. Statistics results $(F, p)$ have been presented in figure legends. Values of $p<0.05$ were considered to be statistically significant.

\section{Materials}

6-OHDA bromide, benserazide hydrochloride, bicuculline methochloride, and L-dopa methyl ester were purchased from Sigma. Lidocaine hydrochloride was purchased from Bioindustria LIM. All drugs were freshly dissolved in isosmotic saline solution just before use.
At the end of these procedures, sections were captured using a computerinterfaced light microscopy workstation (Axioskop, Zeiss) with a highresolution digital camera (AxioCam ICc3, Zeiss).

Nissl staining. For each animal, some cortical sections were mounted on chrome-alum-coated slides, stained with cresyl violet, dried in escalating alcohol concentration, cleared in xylene, and coverslipped with mounting medium to verify needle and microelectrode location.

TH immunohistochemistry. Five sections from each animal were obtained from the region spanning bregma -0.5 to $+1.5 \mathrm{~mm}$, rinsed 3 times in KPBS and incubated for $15 \mathrm{~min}$ in $3 \% \mathrm{H}_{2} \mathrm{O}_{2}$ and $10 \%$ methanol in KPBS to block the endogenous peroxidase activity. After washing in KPBS, the sections were preincubated in blocking serum $5 \%$ normal horse serum and $0.3 \%$ Triton $\times 100$ in PBS) for $60 \mathrm{~min}$, followed by

\section{Results}

Time course of the effects of 6-OHDA (experiment 1)

Motor tests, ICMS, and histological evaluations were performed in control (i.e., before lesioning; $n=5$ ) and 6-OHDAhemilesioned rats at different time points after lesion $(3,15,30$, 60 , and $120 \mathrm{~d} ; n=5$ each). Sham-operated rats were tested at 3 and $15 \mathrm{~d}(n=5$ each) after vehicle injection. Vehicle did not produce behavioral or functional changes (data not shown).

\section{6-OHDA induced DA denervation and reduced motor activity} Unilateral 6-OHDA injection caused a marked loss of striatal DA terminals selectively in the hemisphere ipsilateral to the lesion 
(Fig. 1A). Denervation was significant in the ventral but not dorsolateral striatum already at $3 \mathrm{~d}$ after lesion. At later stages, both regions were almost totally ( $~ 99 \%)$ denervated. Basal activity of rats before 6-OHDA was $2.7 \pm 0.1 \mathrm{~s}$ (immobility time in the bar test), $10.2 \pm$ 0.2 steps (drag test), and $10.9 \pm 0.1$ swings (elevated body swing test). 6-OHDA lesioning caused a marked and bilateral increase of immobility time in bar test (Fig. 1B), a severe and prolonged decrease of the number of steps at the contralateral limb (Fig. 1C), and swings toward the contralateral side (Fig. 1D).

\section{6-OHDA altered M1 excitability}

ICMS was performed in parallel with behavioral testing. Examination of M1 maps after 6-OHDA injection (Fig. 2A-G, examples) revealed several bilateral changes in movement representations. A global decrease of excitability was consistently observed within M1.

Representation size. 6-OHDA-treated rats exhibited a widening of the unexcitable area in M1 (see Materials and Methods) compared to control animals (Fig. $3 A$ ). The effect was larger in the lesioned side than the unlesioned side, maximal at $15 \mathrm{~d}$ in both hemispheres, and still evident albeit attenuated up to $120 \mathrm{~d}$. 6-OHDA caused a bilateral decrease in the size of the vibrissa area only at 3 and $15 \mathrm{~d}$ after lesion (Fig. 3B). Both the caudal (Fig. 3C) and rostral (Fig. 3D) forelimb areas were found to be reduced in the lesioned side from day 15 onward. Surprisingly, a strong increase in the rostral forelimb area was observed at $3 \mathrm{~d}$ in the unlesioned side.

Threshold current. 6-OHDA caused a bilateral increase of threshold currents (i.e., reduced excitability) in the vibrissa area at 3 and $15 \mathrm{~d}$ (Fig. $3 E$ ), the increase being greater in the lesioned side than in unlesioned side. A slight increase in threshold values was observed also at later stages (i.e., 60 and $120 \mathrm{~d}$ ) in the lesioned side. In the forelimb area, a bilateral increase in threshold values was found already at $15 \mathrm{~d}$ (Fig. $3 F$ ), with no difference between caudal and rostral regions (data not shown).

\section{6-OHDA altered ICMS-evoked movements}

To assess the type of muscles recruited during movement, the frequency of ipsilateral and contralateral movements in response to M1 stimulation in the lesioned and unlesioned hemispheres was evaluated. In addition, the frequency of proximal and distal forelimb movements was monitored. 6-OHDA caused an increase of the frequency of movements ipsilateral to the stimulated M1 as well as an increase of the recruitment of proximal movements.

Vibrissa. Under control conditions, M1 stimulation at threshold current elicited vibrissa movements almost totally in the contralateral side of the body (Fig. 4A,B). 6-OHDA caused an
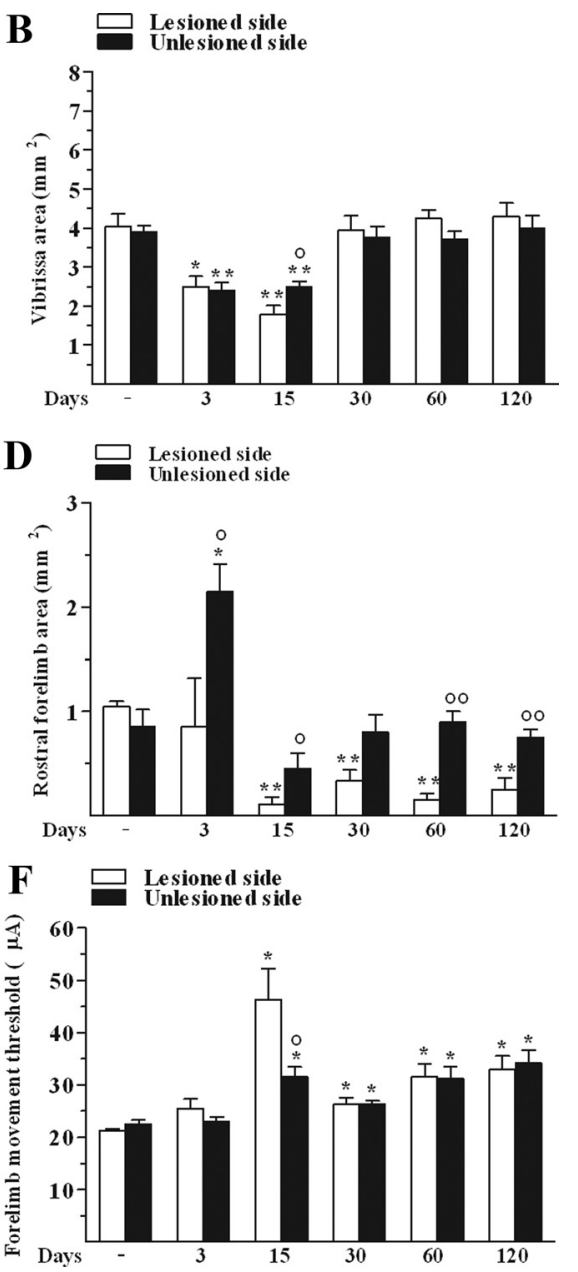

Figure 3. Unilateral 6-OHDA injection in rats changed M1 excitability. 6-0HDA affected the size (in $\mathrm{mm}^{2}$ ) of unexcitable $(\boldsymbol{A})$, vibrissa $(\boldsymbol{B})$, caudal $(\boldsymbol{C})$, and rostral forelimb $(\boldsymbol{D})$ areas as well as threshold currents (in $\mu \mathrm{A})$ in vibrissa $(\boldsymbol{E})$ and forelimb $(\boldsymbol{F})$ areas in both the lesioned side and unlesioned side. All measures were performed in control and 6-0HDA rats at 3, 15, 30,60, and 120 d after $0.0001)$, time $\left(F_{(5,40)}=19.60, p<0.0001\right)$, and time $\times$ treatment interaction $\left(F_{(5,40)}=3.12, p=0.0180\right)$. $\boldsymbol{B}$, Effect of treatment $\left(F_{(1,4)}=2.07, p=0.22\right)$, time $\left(F_{(5,40)}=20.30, p<0.0001\right)$, but not time $\times$ treatment interaction $\left(F_{(5,40)}=1.17, p=0.34\right) . C$ 74, $p=0.03)$. $D$, Effect of treatment $\left(F_{(1,4)}=51.48, p=0.0020\right)$, time $\left(F_{(5,40)}=11.34, p<0.0001\right)$, and time $\times$ treatment teraction $\left(F_{(5,40)}=3.58, p=0.0091\right)$. $\boldsymbol{E}$, Effect of treatment $\left(F_{(1,4)}=50.07, p=0.0021\right)$, time $\left(F_{(5,40)}=11.47, p<0.0001\right)$ $F=1.11, p=0.24)$ and significant different from control; ${ }^{\circ} p<0.05,{ }^{\circ} p<0.01$ different from the lesioned side (RM ANOVA followed by contrast analysis and the sequentially rejective Bonferroni's test for multiple comparisons).

increase of the frequency of ipsilateral (mono or bilateral) movements evoked by stimulation in the lesioned side. The effect was significant at 30 and $60 \mathrm{~d}$ after lesion (Fig. $4 \mathrm{~A}$ ). Stimulation in the unlesioned side (Fig. $4 B$ ) also increased the frequency of ipsilateral movements, but only at $30 \mathrm{~d}$.

Forelimb. As for vibrissa, M1 stimulation under control conditions evoked almost totally contralateral forelimb movements (Fig. 4C,D), distal movements predominating over the proximal ones (Fig. $4 E, F$ ). M1 stimulation in the lesioned side increased the frequency of ipsilateral movements at $30 \mathrm{~d}$ after lesion (Fig. 4C), whereas no change was observed in the unlesioned side (Fig. 4D). 6-OHDA also caused a bilateral shrinkage of the area eliciting distal movements at all time points examined and maximally at $30 \mathrm{~d}$ after lesion (Fig. $4 E$ ), although in the unlesioned side the effect was not significant at 60 and $120 \mathrm{~d}$ after lesion (Fig. $4 F$ ). 
Lesioned side

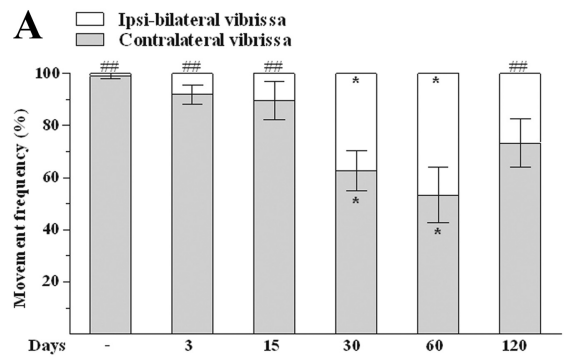

C $\square$ Ipsi-bilateral forelimb

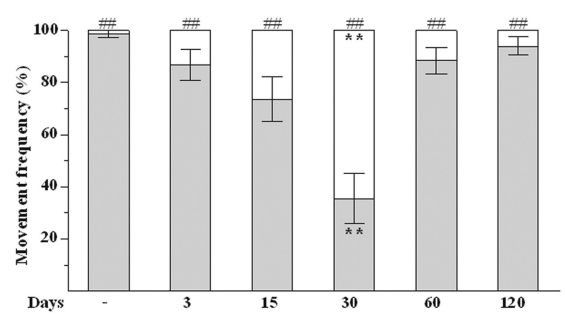

E $\square$ Proximal forelimb

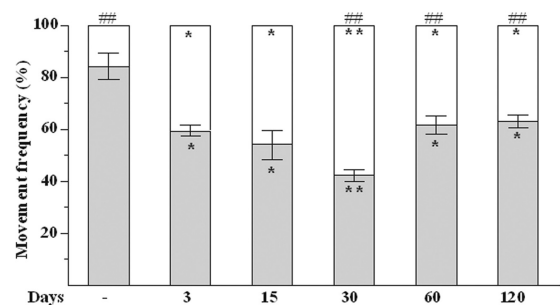

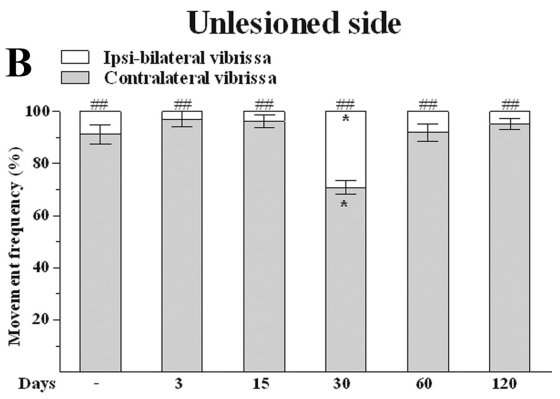

D $\square$ Ipsi-bilateral forelimb

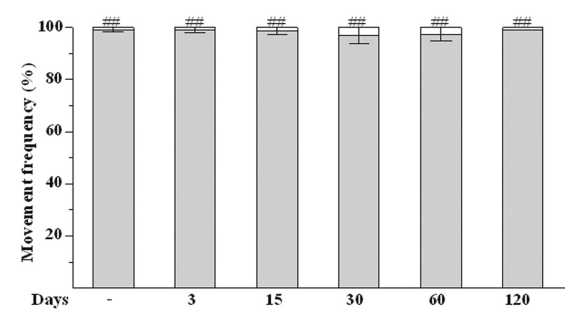

F $\square \underset{\text { Proximal forelimb }}{\text { Distal forelimb }}$

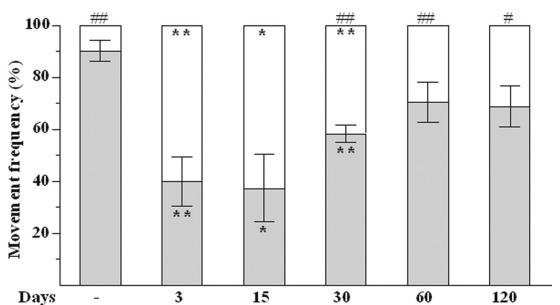

Figure 4. Unilateral 6-OHDA injection in rats changed the type of ICMS-evoked movements. 6-OHDA affected the frequency of ipsi-bilateral and contralateral vibrissa $(\boldsymbol{A}, \boldsymbol{B})$ and forelimb $(\boldsymbol{C}, \boldsymbol{D})$ movements as well as the frequency of distal and proximal forelimb movements $(\boldsymbol{E}-\boldsymbol{F})$ in both the lesioned side and unlesioned side. All measures were performed in control and 6-0HDA rats at 3, 15, 30,60, and $120 \mathrm{~d}$ after lesion. Data are means \pm SEM of five determinations per group and are expressed as percentage of total movements. Statistical results: $\boldsymbol{A}$, Effect of treatment $\left(F_{(1,4)}=217.30, p=0.0001\right)$ but not of time $\left(F_{(5,40)}=0.01, p=\right.$ $0.99)$ and time $\times$ treatment interaction $\left(F_{(5,40)}=10.68, p<0.0001\right)$. $\boldsymbol{B}$, Effect of treatment $\left(F_{(1,4)}=1490.55, p<0.0001\right)$ but not time $\left(F_{(5,40)}=0.01, p=0.99\right)$, and time $\times$ treatment interaction $\left(F_{(5,40)}=21.87, p<0.0001\right)$. C, Effect of treatment $\left(F_{(1,4)}=98.11, p=0.0006\right)$ but not time $\left(F_{(5,40)}=0.01, p=0.99\right)$ and time $\times$ treatment interaction $\left(F_{(5,40)}=27.88, p<\right.$ 0.0001). D, Effect of treatment $\left(F_{(1,4)}=7332.12, p<0.0001\right)$ but not time $\left(F_{(5,40)}=0.01, p=0.99\right)$ or time $\times$ treatment interaction $\left(F_{(5,40)}=0.85, p=0.52\right)$. $\boldsymbol{E}$, Effect of treatment $\left(F_{(1,4)}=91.80, p=0.0007\right)$ but not time $\left(F_{(5,40)}=0.01, p=0.99\right)$

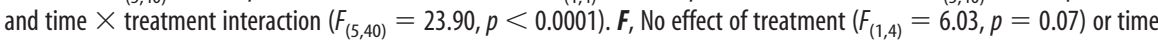
$\left(F_{(5,40)}=0.01, p=0.99\right)$, but significant time $\times$ treatment interaction $\left(F_{(5,40)}=13.96, p<0.0001\right) .{ }^{*} p<0.05,{ }^{* *} p<0.01$ different from control; ${ }^{*} p<0.05,{ }^{\# \#} p<0.01$ different from contralateral $(\boldsymbol{A}-\boldsymbol{D})$ or distal $(\boldsymbol{E}, \boldsymbol{F})$ movements (RM ANOVA followed by contrast analysis and the sequentially rejective Bonferroni's test for multiple comparisons).

\section{Pharmacological investigations in 6-OHDA-treated rats (experiment 2) \\ L-Dopa partially restored motor function and M1 output}

To investigate the involvement of endogenous DA in the 6-OHDA-induced abnormalities, the ability of L-dopa $(6 \mathrm{mg} / \mathrm{kg}$ with benserazide $15 \mathrm{mg} / \mathrm{kg}$; i.p.) to rescue movement and M1 output was investigated at 15 and $60 \mathrm{~d}$ after lesion ( $n=5$ each).

Behavioral tests. L-Dopa had no effect in control rats but ameliorated motor performance deficits in 6-OHDA-hemilesioned rats (Fig. 5), reducing the immobility time (Fig. 5A) and increasing both the number of steps (Fig. $5 B$ ) and swings (Fig. 5C) at the contralateral side. L-Dopa had similar efficacy at 15 and $60 \mathrm{~d}$ after lesion.

Representation size. Examination of M1 maps $10 \mathrm{~min}$ after L-dopa administration revealed that L-dopa tended to normalize the size of the unexcitable area in the lesioned side, its effect being stronger at 15 than at $60 \mathrm{~d}$ (Fig. $6 \mathrm{~A}$ ). Normalization in the sizes of vibrissa (Fig. 6B) and caudal forelimb (Fig. 6C) areas was ob- served. Conversely, L-dopa failed to rescue the normal size of the rostral forelimb area (Fig. 6D).

Threshold current. L-Dopa failed to restore the normal threshold current values both in the vibrissa (Fig. $6 E$ ) and forelimb (Fig. $6 F$ ) areas. The only effect was an attenuation of the increase in threshold current at $15 \mathrm{~d}$.

Forelimb movement. No significant changes in movement lateralization were observed at 15 and $60 \mathrm{~d}$ after 6-OHDA, although L-dopa slightly decreased the frequency of contralateral movement at 60 d (Fig. 6G). More relevant, L-dopa normalized the frequency of forelimb distal movements both at 15 and $60 \mathrm{~d}$ after lesion (Fig. $6 H$ ).

Bicuculline partially restored M1 output Since systemic L-dopa did not fully restore cortical output in 6-OHDA-lesioned rats, we tested the hypothesis that functional changes could also be caused by intracortical GABAergic mechanisms, which are known to play a major role in maintaining or readjusting motor representations (Jacobs and Donoghue, 1991). The ability of the $\mathrm{GABA}_{\mathrm{A}}$ receptor antagonist bicuculline $(50 \mu \mathrm{M})$ to reverse $\mathrm{M} 1$ changes at the lesioned side was investigated at the same time points of L-dopa (15 and $60 \mathrm{~d}$ after lesion; $n=5$ each). To allow bicuculline diffusion through the cortical layers, dura was removed in a limited region of M1, representing the rostral forelimb and partially the vibrissa and caudal forelimb areas. Bicuculline partially restored M1 output at both 15 and $60 \mathrm{~d}$ (Fig. 7).

Representation size. In control rats $(n=5)$, bicuculline decreased the unexcitable area (Fig. 7A), increased the size of the vibrissa area (Fig. $7 B$ ), and decreased the size of the caudal (Fig. $7 C$ ) without affecting that of the rostral (Fig. 7D) forelimb areas. In lesioned rats, bicuculline attenuated the increase in the unexcitable area induced by 6-OHDA at both 15 and $60 \mathrm{~d}$ after lesion (Fig. $7 A$ ) and normalized the size of the vibrissa (Fig. $7 B$ ) and the rostral forelimb (Fig. 7D) areas. A trend for normalization was also observed in the caudal forelimb area (Fig. 7C).

Threshold current. Bicuculline produced a mild reduction (i.e., increased excitability) of threshold currents in the vibrissa (Fig. $7 E$ ) and forelimb (Fig. $7 F$ ) areas of control rats and normalized them in parkinsonian rats, the effect being more evident in the vibrissa area.

Forelimb movement. Bicuculline did not affect the frequency of contralateral movements (Fig. $7 G$ ) and decreased that of distal movements (Fig. $7 H$ ) in control rats. No change in lateralization was induced by 6-OHDA, although bicuculline decreased the frequency of contralateral movement at $60 \mathrm{~d}$ (Fig. $7 \mathrm{G}$ ). Moreover, bicuculline failed to reverse the reduction in distal movement induced by 6-OHDA (Fig. $7 H$ ). 

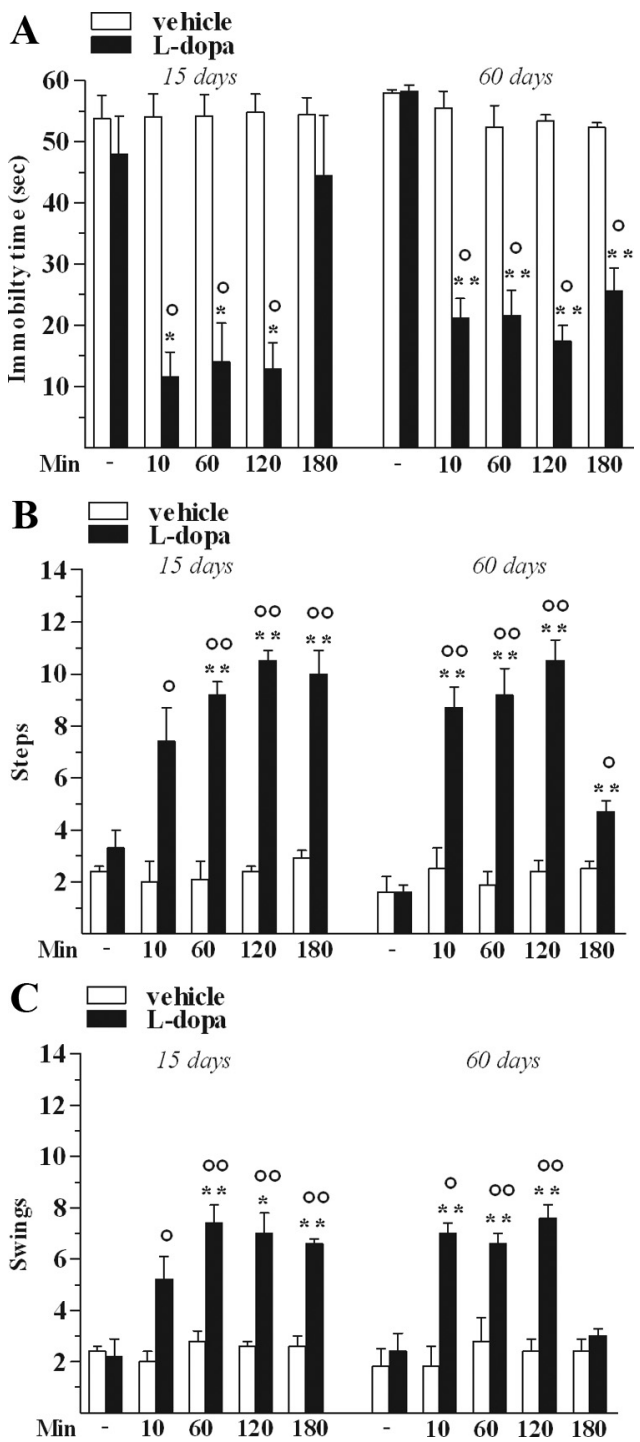

Figure 5. L-Dopa attenuated motor deficits in 6-OHDA-treated rats. L-Dopa $(6 \mathrm{mg} / \mathrm{kg}$ plus benserazide $15 \mathrm{mg} / \mathrm{kg}$, i.p.) increased motor performance in the bar $(\boldsymbol{A}), \operatorname{drag}(\boldsymbol{B})$, and elevated body swing $(C)$ test. All measures were performed before and 10, 60, 120, and 180 min after L-dopa or vehicle administration. Data are means \pm SEM of five determinations per group and are expressed as absolute values (seconds (sec), steps, and swings, respectively). Statistical results: $\boldsymbol{A}$, Left, Effect of treatment $\left(F_{(1,4)}=17.53, p=0.0138\right)$, time $\left(F_{(4,32)}=13.05, p<\right.$ $0.0001)$, and time $\times$ treatment interaction $\left(F_{(4,32)}=13.46, p<0.0001\right)$. Right, Effect of treatment $\left(F_{(1,4)}=165.08, p=0.0002\right)$, time $\left(F_{(4,32)}=26.68, p<0.0001\right)$, and time $\times$ treatment interaction $\left(F_{(4,32)}=16.82, p<0.0001\right)$. B, Left, Effect of treatment $\left(F_{(1,4)}=\right.$ $290.89, p<0.0001)$, time $\left(F_{(4,32)}=13.11, p<0.0001\right)$, and time $\times$ treatment interaction $\left(F_{(4,32)}=11.80, p<0.0001\right)$. Right, Effect of treatment $\left(F_{(1,4)}=292.67, p=0.0002\right)$, time $\left(F_{(4,32)}=16.37, p<0.0001\right)$, and time $\times$ treatment interaction $\left(F_{(4,32)}=12.92, p<\right.$ 0.0001). C, Left, Effect of treatment $\left(F_{(1,4)}=41.97, p=0.0029\right)$, time $\left(F_{(4,32)}=9.35, p<\right.$ $0.0001)$, and time $\times$ treatment interaction $\left(F_{(4,32)}=6.98, p=0.0004\right)$. Right, Effect of treatment $\left(F_{(1,4)}=23.12, p=0.0086\right)$, time $\left(F_{(4,32)}=12.09, p<0.0001\right)$, and time $\times$ treatment interaction $\left(F_{(4,32)}=9.82, p<0.0001\right) .{ }^{*} p<0.05,{ }^{* *} p<0.01$ different from control; ${ }^{\circ} p<$ $0.05,{ }^{\circ} p<0.01$ different from vehicle (RM ANOVA followed by contrast analysis and the sequentially rejective Bonferroni's test for multiple comparisons).

\section{Lidocaine restored lateralization of movements}

Since in the lesioned side we found a robust increase of ipsilateral movements in the forelimb area at $30 \mathrm{~d}$, we investigated the contribution of the opposite hemisphere. Indeed, in naive animals ipsilateral movements evoked in the M1 of one hemisphere depend on the function of the homotopic M1 (Brus-Ramer et al., 2009). The voltage-dependent $\mathrm{Na}^{+}$channel blocker lidocaine
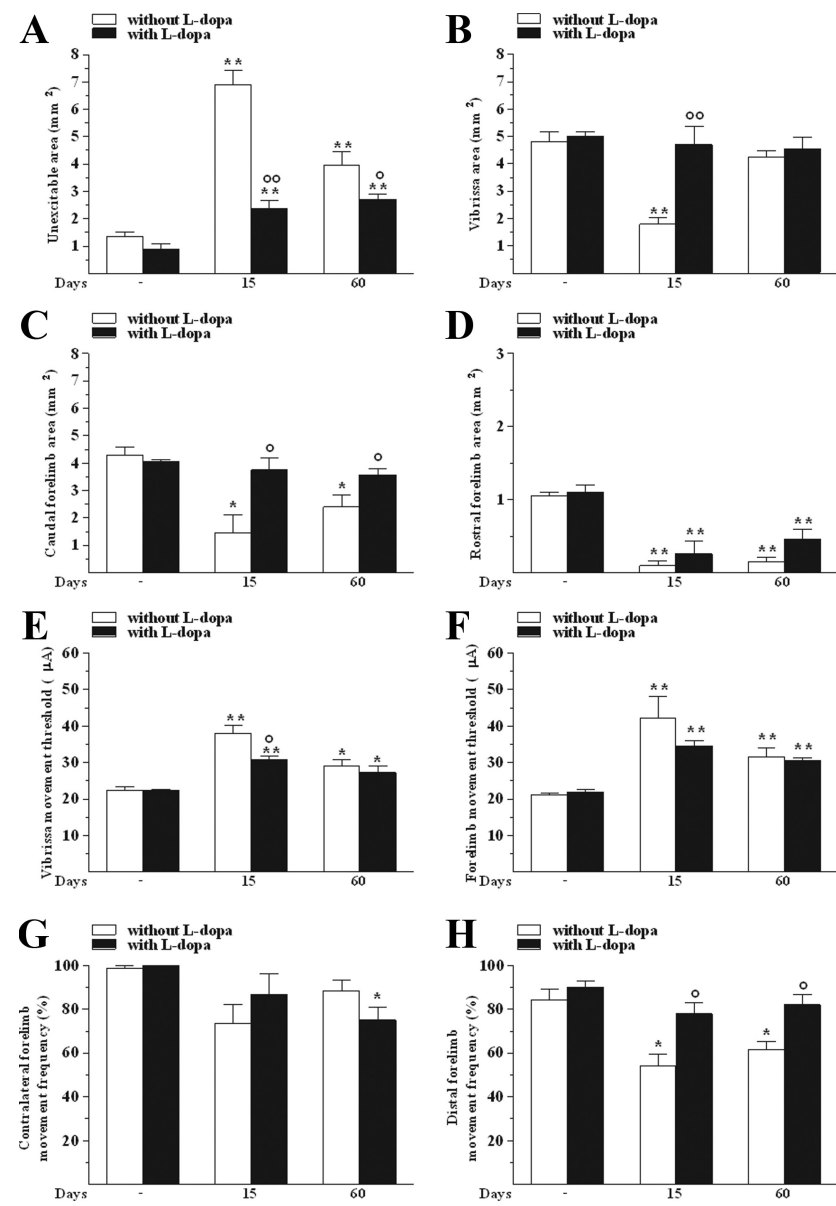

Figure 6. L-Dopa partially restored M1 output in 6-OHDA-treated rats. L-Dopa $(6 \mathrm{mg} / \mathrm{kg}$ plus benserazide, $15 \mathrm{mg} / \mathrm{kg}$, i.p.) affected the size (in $\mathrm{mm}^{2}$ ) of unexcitable $(\boldsymbol{A})$, vibrissa $(\boldsymbol{B})$, caudal $(\boldsymbol{C})$, and rostral forelimb $(\boldsymbol{D})$ areas, the threshold current (in $\mu \mathrm{A}$ ) in vibrissa $(\boldsymbol{E})$ and forelimb $(\boldsymbol{F})$ areas, and the frequency (in percentage of total movements) of contralateral $(\boldsymbol{G})$ and distal $(\boldsymbol{H})$ forelimb movements. All measures were performed in control and 6-OHDA rats at 15 and $60 \mathrm{~d}$ after lesion. Data are means \pm SEM of five determinations per group. Statistical results: $\boldsymbol{A}$ Effect of treatment $\left(F_{(1,4)}=28.34, p=0.0060\right)$, time $\left(F_{(2,16)}=53.07, p<0.0001\right)$, and time $\times$ treatment interaction $\left(F_{(2,16)}=19.61, p<0.0001\right)$. $\boldsymbol{B}$, Effect of treatment $\left(F_{(1,4)}=\right.$ $11.88, p=0.0261)$, time $\left(F_{(2,16)}=11.42, p=0.0008\right)$, and time $\times$ treatment interaction $\left(F_{(2,16)}=9.56, p<0.0019\right)$. C, Effect of treatment $\left(F_{(1,4)}=7.89, p=0.0483\right)$, time $\left(F_{(2,16)}=\right.$ $7.57, p=0.0049)$, and time $\times$ treatment interaction $\left(F_{(2,16)}=4.58, p=0.0267\right)$. D, Effect of time $\left(F_{(2,16)}=46.81, p<0.0001\right)$ but not treatment $\left(F_{(1,4)}=2.57, p=0.18\right)$ or time $X$ treatment interaction $\left(F_{(2,16)}=0.85, p=0.45\right)$. E, Effect of time $\left(F_{(2,16)}=33.35, p<0.0001\right)$ but not treatment $\left(F_{(1,4)}=5.34, p=0.08\right)$ or time $\times$ treatment interaction $\left(F_{(2,16)}=3.26\right.$, $p=0.06)$. $F$, Effect of time $\left(F_{(2,16)}=28.16, p<0.0001\right)$ but not treatment $\left(F_{(1,4)}=1.67, p=\right.$ $0.27)$ or time $\times$ treatment interaction $\left(F_{(2,16)}=3.53, p=0.05\right)$. G, Effect of time $\left(F_{(2,16)}=\right.$ $8.46, p=0.0031)$ but not treatment $\left(F_{(1,4)}=0.06, p=0.81\right)$ or time $\times$ treatment interaction $\left(F_{(2,16)}=3.32, p=0.06\right)$. $\boldsymbol{H}$, Effect of treatment $\left(F_{(1,4)}=36.06, p=0.0039\right)$ and time $\left(F_{(2,16)}=9.64, p=0.0018\right)$ but not time $\times$ treatment interaction $\left(F_{(2,16)}=1.85, p=0.19\right)$. ${ }^{*} p<0.05,{ }^{* *} p<0.01$ different from control without and with L-dopa; ${ }^{\circ} p<0.05,{ }^{\circ 0} p<0.01$ different from vehicle (RM ANOVA followed by contrast analysis and the sequentially rejective Bonferroni's test for multiple comparisons).

was injected into the forelimb area of the unlesioned side (Fig. $8 A$ ) to inactivate it. ICMS-evoked responses were then evaluated in the lesioned side $(n=5)$ at $30 \mathrm{~d}$ after lesion. Lidocaine did not affect the increase in ipsilateral movement in the vibrissa area (Fig. $8 \mathrm{~B}$ ) but restored the physiological lateralization in the forelimb area (Fig. 8C).

\section{Discussion}

6-OHDA lesion was associated with marked striatal DA denervation and prolonged motor impairment. Akinesia (bar test) was 

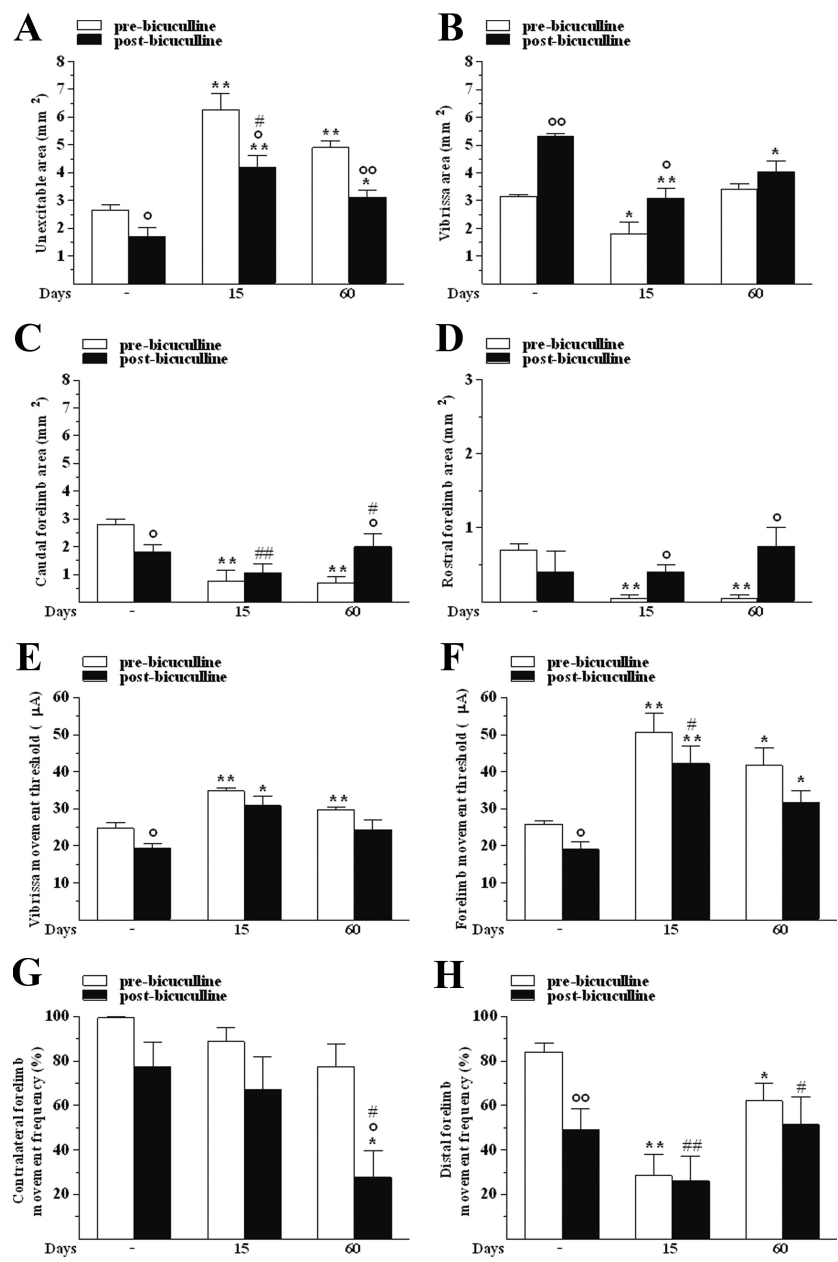

Figure 7. Bicuculline partially restored M1 output in 6-OHDA-treated rats. Cortical application of bicuculline (50 $\mu \mathrm{m}$ ) affected the size (in $\mathrm{mm}^{2}$ ) of unexcitable $(\boldsymbol{A})$, vibrissa $(\boldsymbol{B})$, caudal $(\boldsymbol{C})$, and rostral forelimb $(\boldsymbol{D})$ areas, the threshold current $(\mu \mathrm{A})$ in vibrissa $(\boldsymbol{E})$ and forelimb $(\boldsymbol{F})$ areas, and the frequency (percentage of total movements) of contralateral $(\boldsymbol{G})$ and distal $(\boldsymbol{H})$ forelimb movements. All measures were performed before and after drug treatment in control and 6-OHDA rats at 15 and $60 \mathrm{~d}$ after lesion. Data are means \pm SEM of five determinations per group. Statistical results: $A$, Effect of treatment $\left(F_{(1,4)}=27.23, p=0.0064\right)$ and time $\left(F_{(2,16)}=\right.$ $27.97, p<0.0001)$ but not significant time $\times$ treatment interaction $\left(F_{(2,16)}=0.99, p=0.39\right)$. $\boldsymbol{B}$, Effect of treatment $\left(F_{(1,4)}=45.90, p=0.0025\right)$ and time $\left(F_{(2,16)}=18.17, p=0.0001\right)$ but not time $\times$ treatment interaction $\left(F_{(2,16)}=3.07, p=0.07\right)$. C, Effect of time $\left(F_{(2,16)}=7.18\right.$, $p=0.0060)$ but not treatment $\left(F_{(1,4)}=1.10, p=0.35\right)$ and time $\times$ treatment interaction $\left(F_{(2,16)}=4.67, p=0.0252\right)$. D, No effect of treatment $\left(F_{(1,4)}=4.09, p=0.11\right)$ or time $\left(F_{(2,16)}\right.$ $=1.71, p=0.21)$ but a significant time $\times$ treatment interaction $\left(F_{(2,16)}=4.16, p=0.0351\right)$. $\boldsymbol{E}$, Effect of treatment $\left(F_{(1,4)}=25.21, p=0.0074\right)$ and time $\left(F_{(2,16)}=15.02, p=0.0002\right)$ but not time $\times$ treatment interaction $\left(F_{(2,16)}=0.09, p=0.92\right)$. $\boldsymbol{F}$, Effect of treatment $\left(F_{(1,4)}=\right.$ $37.69, p=0.0036)$ and time $\left(F_{(2,16)}=15.18, p=0.0002\right)$ but not time $\times$ treatment interaction $\left(F_{(2,16)}=0.07, p=0.93\right)$. $\mathbf{G}$, Effect of time $\left(F_{(2,16)}=16.54, p=0.0001\right)$ but not treatment $\left(F_{(1,4)}=6.45, p=0.06\right)$ or time $\times$ treatment interaction $\left(F_{(2,16)}=3.12, p=0.07\right)$. $\boldsymbol{H}$, Effect of time $\left(F_{(2,16)}=9.49, p<0.0019\right)$ but not treatment $\left(F_{(1,4)}=2.55, p=0.19\right)$ or time $\times$ treatment interaction $\left(F_{(2,16)}=1.62, p=0.23\right) .{ }^{*} p<0.05,{ }^{* *} p<0.01$ different from respective control; ${ }^{\circ} p<0.05$ and ${ }^{\circ 0} p<0.01$ different from pre-bicuculline; ${ }^{\#} p<0.05$ and ${ }^{\# \#} p<0.01$ different from pre-bicuculline before 6-0HDA (RM ANOVA followed by contrast analysis and the sequentially rejective Bonferroni's test for multiple comparisons).

bilateral throughout and evident already at $3 \mathrm{~d}$ whereas a clear asymmetry emerged in the drag and elevated body swing tests, i.e., when the animal was forced to prolonged movement. In these tests, motor disability affected mainly (drag test) or exclusively (swing test) the contralateral side of the body and correlated well with DA depletion in the dorsolateral (motor) striatum, as both were maximal at $15 \mathrm{~d}$ after lesion.
Cortical changes after 6-OHDA treatment

M1 excitability markedly decreased after 6-OHDA. Overall, cortical changes were time dependent and bilateral, although stronger in the lesioned than in the intact hemisphere. Interestingly, changes in both vibrissa and forelimb motor areas were evident already at $3 \mathrm{~d}$, when the dorsolateral striatum was not significantly denervated. However, a TH-positive staining is only a functional marker and does not necessarily imply cell vitality. The vibrissa area showed marked decrease in size and excitability in both hemispheres at 3 and $15 \mathrm{~d}$. These perturbations may reflect a reduced activity of excitatory interhemispheric connections between the homotopic vibrissa areas (Maggiolini et al., 2007). Since vibrissae are used to acquire sensory information (Kleinfeld et al., 2006), an exploratory spatial deficit may occur in 6-OHDAlesioned rats, although testing this hypothesis was beyond the scopes of the study. The forelimb area at the ipsilateral side showed persistent decrease in size and excitability, the rostral area being more affected than the caudal one. This may explain the impairment in the skilled reaching movement in hemiparkinsonian rats (Miklyaeva et al., 1994; Whishaw et al., 1997; Metz et al., 2001), since the complex sequences of reach-to-grasp movement are represented in the rostral forelimb area (Ramanathan et al., 2006), which is homologous to the premotor/supplementary motor area of primates (Rouiller et al., 1993). Surprisingly, the size of the contralateral rostral forelimb area appeared increased after $3 \mathrm{~d}$. This short-term reorganization was probably due to the preserved plasticity of the forelimb in the unlesioned hemisphere. Indeed, vibrissa and forelimb areas interact to define their border (Maggiolini et al., 2008). Overall, our findings support previous evidence for reduced cortical activation in 6-OHDAhemilesioned rats as revealed by reduced metabolic activity (Orieux et al., 2002) and immediate-early gene expression (Steiner and Kitai, 2000) in the frontal cortex. Two previous ICMS studies in 6-OHDA-hemilesioned rats failed to detect functional changes in the ipsilateral forelimb area, not providing information on M1 function in the unlesioned hemisphere (Metz et al., 2004; Brown et al., 2009). In contrast, we found a bilateral reduction of forelimb area size and an increase in threshold current in the forelimb area. This discrepancy may be explained with the lower degree of striatal DA denervation in one case (Brown et al., 2009) and the use of desmethylimipramine to protect noradrenergic fibers from 6-OHDA in the other (Metz et al., 2004). However, Brown et al. (2009) observed a global reduction in the forelimb area size when 6-OHDA was injected bilaterally. In line with the present study, reports in PD patients showed that DA loss caused a dynamic process of cortical reorganization, as demonstrated by a shift in the corticomotor representation of the hand (Thickbroom et al., 2006) and the progressive changes in regional metabolism at key nodes of motor networks (Huang et al., 2007). Reduced baseline excitability of motor areas and their time-dependent reorganization support the classical model of basal ganglia function in PD that posits a reduced frontal cortex activity due to changes in firing frequency (hyperactivity) and pattern discharge in nigral output neurons (Alexander and Crutcher, 1990; Wichmann and DeLong, 2003; Braak and Del Tredici, 2008). The possibility that cortical changes are due to chronic immobility rather than DA denervation should be considered. However, not only 6-OHDA lesioning but also acute haloperidol administration reduced M1 excitability (Brown et al., 2009). Moreover, L-dopa partially reversed these cortical deficits. Therefore, cortical changes are likely 
A

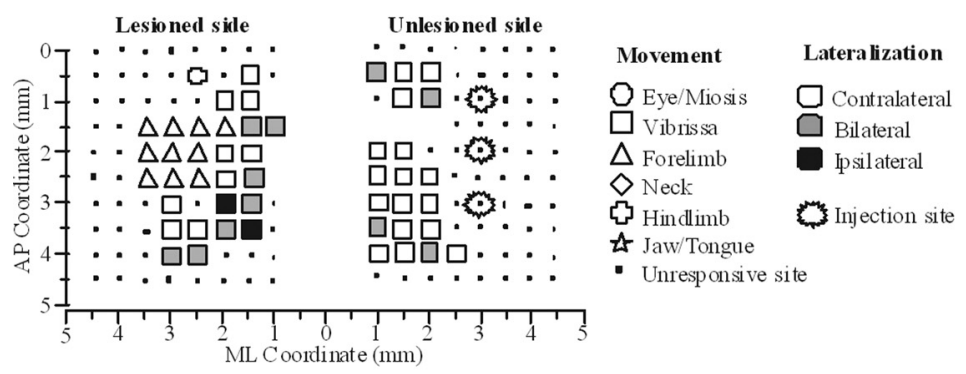

B

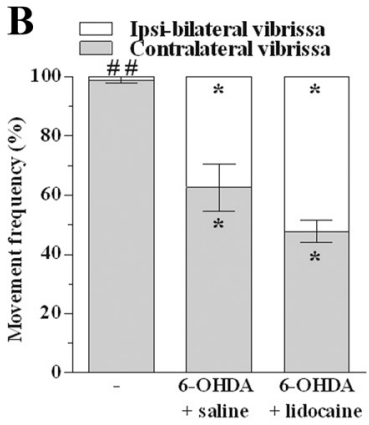

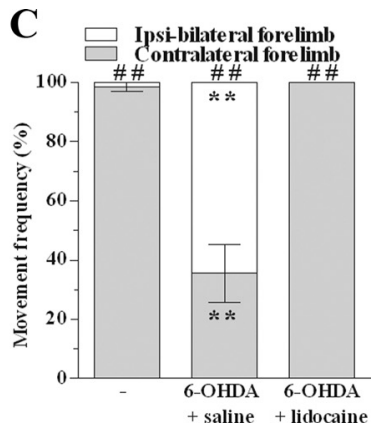

Figure 8. Lidocaine restored movement lateralization in 6-OHDA-treated rats. $\boldsymbol{A}$, Representative bilateral $\mathrm{M} 1$ map of movements evoked at threshold current after intracortical injections of lidocaine (3\% in saline) in 6-0HDA rats at $30 \mathrm{~d}$ after lesion. The microelectrode was sequentially introduced to a depth of $1500 \mu \mathrm{m}$. Interpenetration distances were $500 \mu \mathrm{m}$. In these mapping schemes, frontal poles are at the bottom. Zero (0) corresponds to bregma, and numbers indicate rostral distance from the bregma or lateral distance from the midline. Movement evoked at one point is indicated by symbols and movement lateralization by different gray scale. Absence of symbol (within or at the border of the map) indicates that penetration was not performed due to presence of a large vessel. Lidocaine injected in forelimb area of the unlesioned side (injected sites are marked with star circles) restored movement lateralization in the forelimb $(\boldsymbol{C})$ but not vibrissa $(\boldsymbol{B})$ area of the lesioned side. Data are means \pm SEM of five determinations per group. Statistical results: $\boldsymbol{B}$, Effect of treatment $\left(F_{(5,29)}=34.02, p<0.0001\right)$. $\boldsymbol{C}$, Effect of treatment $\left(F_{(5,29)}=62.15, p<\right.$ $0.0001) .{ }^{*} p<0.05,{ }^{* *} p<0.01$ different from control; ${ }^{\# \#} p<0.01$ different from frequency of contralateral movement (ANOVA followed by the Newman-Keuls test for multiple comparisons).

a consequence of striatal DA depletion rather than behavioral deprivation.

A time-dependent modulation was also found in the type of represented movement. It is well known that both ipsilateral and contralateral movements can be evoked by M1 stimulation, although a higher threshold current is required to evoke the ipsilateral ones (Kartje-Tillotson et al., 1985; Liang et al., 1993). 6-OHDA caused a significant widening of the area eliciting ipsilateral movement at threshold current in the lesioned side at 30 and $60 \mathrm{~d}$ after lesion. Since a parallel increase was observed in the extent of motor representations, it can be concluded that recovery of M1 output occurred through corepresentation of contralateral and ipsilateral movements at the same cortical site. Indeed, ipsilateral movement representation in M1 might be an important component of recovery in hemipakinsonian rats, as after unilateral damage of the pyramidal system (Brus-Ramer et al., 2009). Moreover, consistent with previous reports that behavioral changes after unilateral nigrostriatal degeneration are not restricted to the contralateral paw (Vergara-Aragon et al., 2003; Miklyaeva et al., 2007; Woodlee et al., 2008), we found a bilateral decrease in the distal-to-proximal ratio of forelimb representations. This might reflect a loss of skilled movements and be the consequence of a lesion-induced deficit on map expression.

\section{Neurobiological mechanisms underlying M1 changes}

Various mechanisms have been investigated by applying pharmacological treatments at different times after lesion. In particular, L-dopa and bicuculline were applied during the period of maximal cortical depression ( $15 \mathrm{~d}$ ) and during the phase of relative recovery $(60 \mathrm{~d})$. Instead, lidocaine was applied during the period of maximal appearance of ipsilateral movements (30 d).

L-Dopa exerted long lasting antiparkinsonian effects. In parallel, L-dopa totally restored the size in the vibrissa and caudal forelimb areas, being ineffective in the rostral forelimb area. In addition, L-dopa was barely effective in modulating threshold currents (consistent with that reported in patients) (Lefaucheur, 2005) but restored the ability to evoke distal forelimb movements. The lack of effect in the rostral area is consistent with evidence that L-dopa did not improve skilled forelimb movements in hemiparkinsonian rats (Metz et al., 2001). The failure of L-dopa in normalizing all parameters remains puzzling. One possible reason could be a suboptimal dosage, since that the dose of L-dopa was chosen on the basis of symptomatic effects (Marti et al., 2007). Alternatively, the involvement of DA-independent mechanisms cannot be excluded since 6-OHDA also affects non-DA neurons (Deumens et al., 2002), which is in line with the finding that parkinsonian deficiencies have been observed in subcortical non-DAergic structures (e.g., thalamus, brainstem) (Wichmann and DeLong, 2003). Specifically, the involvement of noradrenergic transmission cannot be ruled out because we did not protect noradrenergic neurons from 6-OHDA lesioning with desmethylimipramine, and it is known that noradrenergic neurons modulate the activity of dopaminoceptive striatofugal neurons (Marien et al., 2004), which in turn can affect cortical excitability.

The contribution of intracortical inhibition in maintaining or readjusting cortical motor representations in $\mathrm{PD}$ is not clear. Cortical application of bicuculline has allowed us to demonstrate that GABAergic transmission is critically placed to maintain the form of cortical motor representations (Jacobs and Donoghue, 1991; Benali et al., 2008) and to modulate the functional link between cortical points (Schneider et al. 2002). In the present study, cortical application of bicuculline at a subconvulsive concentration (Stojic et al., 2000) resulted in global increase of M1 excitability. Indeed, experiments in control rats suggest that GABAergic transmission preserves the form of motor representation by focusing cortical output onto distal forelimb muscles. Unlike L-dopa, bicuculline normalized the size of the rostral forelimb area in 6-OHDA rats while being ineffective in directing the motor output on the contralateral distal forelimb muscles. Thus, GABAergic transmission may inhibit the rostral forelimb region and lose the ability to focus the motor output on distal forelimb muscles under DA depletion conditions.

The lesioned side exhibits a larger representation of ipsilateral movement than the unlesioned one. Ipsilateral forelimb responses evoked at the lesioned side were eliminated during inhibition of the corresponding region of the opposite hemisphere (homotopic area) (Netz et al., 1997) by lidocaine. This may suggest that the ipsilateral forelimb representation in the lesioned hemisphere is dependent on the compensatory activity of the unlesioned one. Therefore, under parkinsonian conditions the interhemispheric connections may be dysregulated. Similar changes could be found in humans by observing mirror movements in parkinsonian patients during the early phase of asymmetric PD. Mirror movements are unintended movements on the less affected side accompanying voluntary activity of the more 
affected side due to activation of the contralateral motor cortex (Cincotta et al., 2006; Li et al., 2007).

\section{Concluding remarks}

ICMS revealed a dynamic remodeling of movement representation in the M1 of hemiparkinsonian rats in line with that observed in PD patients. These abnormalities appear to be sustained by subcortical (DA-dependent) and intracortical (GABAdependent) mechanisms as well as by altered interhemispheric connectivity. The correlation between recovery of $\mathrm{M} 1$ parameters and behavioral function in response to L-dopa, although partial, justifies the use of ICMS to shed light on the cortical mechanisms underlying the therapeutic action of antiparkinsonian drugs.

\section{References}

Alexander GE, Crutcher MD (1990) Functional architecture of basal ganglia circuits: neural substrates of parallel processing. Trends Neurosci 13:266-271.

Benali A, Weiler E, Benali Y, Dinse HR, Eysel UT (2008) Excitation and inhibition jointly regulate cortical reorganization in adult rats. J Neurosci 28:12284-12293.

Borlongan CV, Sanberg PR (1995) Elevated body swing test: a new behavioral parameter for rats with 6-hydroxydopamine-induced hemiparkinsonism. J Neurosci 15:5372-5378.

Braak H, Del Tredici K (2008) Cortico-basal ganglia-cortical circuitry in Parkinson's disease reconsidered. Exp Neurol 212:226-229.

Brown AR, Hu B, Antle MC, Teskey GC (2009) Neocortical movement representations are reduced and reorganized following bilateral intrastriatal 6-hydroxydopamine infusion and dopamine type-2 receptor antagonism. Exp Neurol 220:162-170.

Brus-Ramer M, Carmel JB, Martin JH (2009) Motor cortex bilateral motor representation depends on subcortical and interhemispheric interactions. J Neurosci 29:6196-6206.

Buhmann C, Glauche V, Stürenburg HJ, Oechsner M, Weiller C, Büchel C (2003) Pharmacologically modulated fMRI-cortical responsiveness to levodopa in drug-naive hemiparkinsonian patients. Brain 126:451-461.

Cincotta M, Borgheresi A, Balestrieri F, Giovannelli F, Ragazzoni A, Vanni P, Benvenuti F, Zaccara G, Ziemann U (2006) Mechanisms underlying mirror movements in Parkinson's disease: a transcranial magnetic stimulation study. Mov Disord 21:1019-1025.

Deumens R, Blokland A, Prickaerts J (2002) Modeling Parkinson's disease in rats: an evaluation of 6-OHDA lesions of the nigrostriatal pathway. Exp Neurol 175:303-317.

Dick JP, Cowan JM, Day BL, Berardelli A, Kachi T, Rothwell JC, Marsden CD (1984) The corticomotoneurone connection is normal in Parkinson's disease. Nature 310:407-409.

Donoghue JP, Wise SP (1982) The motor cortex of the rat: cytoarchitecture and microstimulation mapping. J Comp Neurol 212:76-88.

Escola L, Michelet T, Douillard G, Guehl D, Bioulac B, Burbaud P (2002) Disruption of the proprioceptive mapping in the medial wall of parkinsonian monkeys. Ann Neurol 52:581-587.

Escola L, Michelet T, Macia F, Guehl D, Bioulac B, Burbaud P (2003) Disruption of information processing in the supplementary motor area of the MPTP-treated monkey: a clue to the pathophysiology of akinesia? Brain 126:95-114.

Franchi G (2000) Reorganization of vibrissal motor representation following severing and repair of the facial nerve in adult rats. Exp Brain Res 131:33-43.

Franchi G (2002) Time course of motor cortex reorganization following botulinum toxin injection into the vibrissal pad of the adult rat. Eur J Neurosci 16:1333-1348.

Friedberg MH, Lee SM, Ebner FF (1999) Modulation of receptive field properties of thalamic somatosensory neurons by the depth of anesthesia. J Neurophysiol 81:2243-2252.

Galvan A, Wichmann T (2008) Pathophysiology of parkinsonism. Clin Neurophysiol 119:1459-1474.

Huang C, Tang C, Feigin A, Lesser M, Ma Y, Pourfar M, Dhawan V, Eidelberg D (2007) Changes in network activity with the progression of Parkinson's disease. Brain 130:1834-1846.

Huntley GW (1997) Correlation between patterns of horizontal connectiv- ity and the extend of short-term representational plasticity in rat motor cortex. Cereb Cortex 7:143-156.

Jacobs KM, Donoghue JP (1991) Reshaping the cortical motor map by unmasking latent intracortical connections. Science 251:944-947.

Kartje-Tillotson G, Neafsey EJ, Castro AJ (1985) Electrophysiological analysis of motor cortical plasticity after cortical lesions in newborn rats. Brain Res 332:103-111.

Kleinfeld D, Ahissar E, Diamond ME (2006) Active sensation: insights from the rodent vibrissa sensorimotor system. Curr Opin Neurobiol $16: 435-444$.

Lefaucheur JP (2005) Motor cortex dysfunction revealed by cortical excitability studies in Parkinson's disease: influence of antiparkinsonian treatment and cortical stimulation. Clin Neurophysiol 116:244-253.

Li JY, Espay AJ, Gunraj CA, Pal PK, Cunic DI, Lang AE, Chen R (2007) Interhemispheric and ipsilateral connections in Parkinson's disease: relation to mirror movements. Mov Disord 22:813-821.

Liang F, Rouiller EM, Wiesendanger M (1993) Modulation of sustained electromyographic activity by single intracortical microstimuli: comparison of two forelimb motor cortical areas of the rat. Somatosens Mot Res $10: 51-61$

Maggiolini E, Veronesi C, Franchi G (2007) Plastic changes in the vibrissa motor cortex in adult rats after output suppression in the homotopic cortex. Eur J Neurosci 25:3678-3690.

Maggiolini E, Viaro R, Franchi G (2008) Suppression of activity in the forelimb motor cortex temporarily enlarges forelimb representation in the homotopic cortex in adult rats. Eur J Neurosci 27:2733-2746.

Marien MR, Colpaert FC, Rosenquist AC (2004) Noradrenergic mechanisms in neurodegenerative diseases: a theory. Brain Res Brain Res Rev 45:38-78.

Marti M, Mela F, Fantin M, Zucchini S, Brown JM, Witta J, Di Benedetto M, Buzas B, Reinscheid RK, Salvadori S, Guerrini R, Romualdi P, Candeletti S, Simonato M, Cox BM, Morari M (2005) Blockade of nociceptin/orphanin FQ transmission attenuates symptoms and neurodegeneration associated with Parkinson's disease. J Neurosci 25:9591-9601.

Marti M, Trapella C, Viaro R, Morari M (2007) The nociceptin/orphanin FQ receptor antagonist J-113397 and L-dopa additively attenuate experimental parkinsonism through overinhibition of the nigrothalamic pathway. J Neurosci 27:1297-1307.

Metz GA, Farr T, Ballermann M, Whishaw IQ (2001) Chronic levodopa therapy does not improve skilled reach accuracy or reach range on a pasta matrix reaching task in 6-OHDA dopamine-depleted (hemi-Parkinson analogue) rats. Eur J Neurosci 14:27-37.

Metz GA, Piecharka DM, Kleim JA, Whishaw IQ (2004) Preserved ipsilateral-to-lesion motor map organization in the unilateral 6-OHDAtreated rat model of Parkinson's disease. Brain Res 1026:126-135.

Miklyaeva EI, Castañeda E, Whishaw IQ (1994) Skilled reaching deficits in unilateral dopamine-depleted rats: impairments in movement and posture and compensatory adjustments. J Neurosci 14:7148-7158.

Miklyaeva EI, Whishaw IQ, Kolb B (2007) A golgi analysis of cortical pyramidal cells in the unilateral parkinson rat: absence of change in the affected hemisphere vs hypertrophy in the intact hemisphere. Restor Neurol Neurosci 25:91-99.

Neafsey EJ, Sievert C (1982) A second forelimb motor area exists in rat frontal cortex. Brain Res 232:151-156.

Neafsey EJ, Bold EL, Haas G, Hurley-Gius KM, Quirk G, Sievert CF, Terreberry RR (1986) The organization of the rat motor cortex: a microstimulation mapping study. Brain Res 396:77-96.

Netz J, Lammers T, Hömberg V (1997) Reorganization of motor output in the non-affected hemisphere after stroke. Brain 120:1579-1586.

Orieux G, François C, Féger J, Hirsch EC (2002) Consequences of dopaminergic denervation on the metabolic activity of the cortical neurons projecting to the subthalamic nucleus in the rat. J Neurosci 22:8762-8770.

Parr-Brownlie LC, Hyland BI (2005) Bradykinesia induced by dopamine D2 receptor blockade is associated with reduced motor cortex activity in the rat. J Neurosci 25:5700-5709.

Paxinos G, Watson C (1982) The rat brain in stereotaxic coordinates. Sydney: Academic.

Pelled G, Bergman H, Goelman G (2002) Bilateral overactivation of the sensorimotor cortex in the unilateral rodent model of Parkinson's disease-a functional magnetic resonance imaging study. Eur J Neurosci 15:389-394.

Ramanathan D, Conner JM, Tuszynski MH (2006) A form of motor cortical 
plasticity that correlates with recovery of function after brain injury. Proc Natl Acad Sci U S A 103:11370-11375.

Rouiller EM, Moret V, Liang F (1993) Comparison of the connectional properties of the two forelimb areas of the rat sensorimotor cortex: support for the presence of a premotor or supplementary motor cortical area. Somatosens Mot Res 10:269-289.

Sabatini U, Boulanouar K, Fabre N, Martin F, Carel C, Colonnese C, Bozzao L, Berry I, Montastruc JL, Chollet F, Rascol O (2000) Cortical motor reorganization in akinetic patients with Parkinson's disease: a functional MRI study. Brain 123:394-403.

Sanberg PR, Bunsey MD, Giordano M, Norman AB (1988) The catalepsy test: its ups and downs. Behav Neurosci 102:748-759.

Sanes JN, Donoghue JP (2000) Plasticity and primary motor cortex. Annu Rev Neurosci 23:393-415.

Sanes JN, Suner S, Donoghue JP (1990) Dynamic organization of primary motor cortex output to target muscles in adult rats. I. Long-term pattern of reorganization following motor or mixed peripheral nerve lesion. Exp Brain Res 79:479-491.

Schallert T, De Ryck M, Whishaw IQ, Ramirez VD, Teitelbaum P (1979) Excessive bracing reactions and their control by atropine and L-DOPA in an animal analog of parkinsonism. Exp Neurol 64:33-43.

Schneider C, Devanne H, Lavoie BA, Capaday C (2002) Neural mechanisms involved in the functional linking of motor cortical areas. Exp Brain Res 146:86-94.

Seiss E, Praamstra P (2004) The basal ganglia and inhibitory mechanisms in response selection: evidence from subliminal priming of motor responses in Parkinson's disease. Brain 127:330-339.
Steiner H, Kitai ST (2000) Regulation of rat cortex function by D1 dopamine receptors in the striatum. J Neurosci 20:5449-5460.

Stojic AS, Lane RD, Killackey HP, Rhoades RW (2000) Suppression of hindlimb inputs to S-I forelimb-stump representation of rats with neonatal forelimb removal: GABA receptor blockade and single-cell responses. J Neurophysiol 83:3377-3387.

Thickbroom GW, Byrnes ML, Walters S, Stell R, Mastaglia FL (2006) Motor cortex reorganisation in Parkinson's disease. J Clin Neurosci 13:639-642.

Toldi J, Laskawi R, Landgrebe M, Wolff JR (1996) Biphasic reorganization of somatotopy in the primary motor cortex follows facial nerve lesion in adult rats. Neurosci Lett 203:179-182.

Vergara-Aragon P, Gonzalez CL, Whishaw IQ (2003) A novel skilledreaching impairment in paw supination on the "good" side of the hemiParkinson rat improved with rehabilitation. J Neurosci 23:579-586.

Whishaw IQ, Coles BL, Pellis SM, Miklyaeva EI (1997) Impairments and compensation in mouth and limb use in free feeding after unilateral dopamine depletions in a rat analog of human Parkinson's disease. Behav Brain Res 84:167-177.

Wichmann T, DeLong MR (2003) Functional neuroanatomy of the basal ganglia in Parkinson's disease. Adv Neurol 91:9-18.

Woodlee MT, Kane JR, Chang J, Cormack LK, Schallert T (2008) Enhanced function in the good forelimb of hemi-parkinson rats: compensatory adaptation for contralateral postural instability? Exp Neurol 211:511-517.

Zarow C, Lyness SA, Mortimer JA, Chui HC (2003) Neuronal loss is greater in the locus coeruleus than nucleus basalis and substantia nigra in Alzheimer and Parkinson diseases. Arch Neurol 60:337-341. 